\title{
Teoria i pràctica del feminisme autònom italià en la dècada dels setanta
}

\author{
Xavier Granell Oteiza \\ UNIVERSITAT DE BARCELONA \\ xavigranell23Rggmail.com
}

Rebut: 01/03/2019

Acceptat: 17/07/2019

\section{RESUM}

En aquest treball fem un recorregut històric i polític pel feminisme de la diferència italià. Amb aquest objectiu, n'analitzarem les aportacions teòriques i les experiències pràctiques. Pel que fa a la teoria, aquest corrent va qüestionar el concepte d'igualtat, en tant que aquest s'havia concebut com a igualtat entre homes, i el marxisme leninisme, pel fet de concebre la classe i el poder de manera masculina. D'altra banda, pel que fa a la pràctica, van formar els grups no mixtos, manifestacions encapçalades només per dones i tota una sèrie d'accions que van trastornar fins i tot els membres del moviment autònom. Durant el període en què s'inscriu (1968-1977) va tenir lloc una gran onada revolucionària i creativa que no podria comprendre's sense l'aparició del feminisme de la diferència i els canvis que va comportar.

Paraules clau: feminisme de la diferència, autonomia, Lonzi, Federici, separació col·lectiva.

\section{ABSTRACT. Theory and Practice of Italian Autonomous Feminism in the 1970s}

In this paper we make a historical and political overview of Italian difference feminism, and for that purpose, we will analyse its theoretical contributions and its practical experiences. Regarding theory, they defied equality inasmuch as this had been considered as equality among men, and Marxism-Leninism for seeing class and power from a masculine perspective; regarding practice, they formed the non-mixed groups, demonstrations leadered only by women and a series of actions that even unsettled the members of the autonomous movement. The time frame of this period (19681977) was a great revolutionary and creative wave that could not be understood without the appearance of difference feminism and the changes that it brought.

Keywords: difference feminism, autonomy, Lonzi, Federici, collective separation.

\author{
SUMARI \\ Introducció \\ Origen i pressupòsits teòrics: desafiant Creont \\ 1975-1976: de l'autoconsciència a la separació col-lectiva \\ Aprenent de la diferència. Lliçons de l'autonomia (a tall de conclusió)
}

Autor per a correspondència / Corresponding author: Xavier Granell Oteiza. Universitat de Barcelona, Facultat de Geografia i Història. Carrer de Montalegre, 6. 08001, Barcelona (Espanya).

Citació suggerida / Suggested citation: Granell Oteiza, X. (2019) Teoria i pràctica del feminisme autònom italià en la dècada de 1970. Debats. Revista de cultura, poder i societat, 133(2), 83-89. DOI: http://doi.org/10.28939/iam.debats.133-2.7 
A Sara García Verdú per descobrir-me el feminisme i a Carles Granell Sales per la seua ajuda.

\section{INTRODUCCIÓ}

El feminisme a què ens referirem és el feminisme de la diferència italià que es va inscriure dins del moviment autònom. En el període que transcorre entre 1968 i 1977, es va produir a Itàlia una explosió de singularitats per mitjà de les quals es va plantejar un desafiament al Partit Comunista Italià, a la patronal, als sindicats, a l'Estat i a les formes de domini imperants en aquell moment.

Si, com planteja el sociòleg Immanuel Wallerstein (2012), el 1968 es va produir una revolució al i del sistema-món, a Itàlia aquesta revolució va continuar almenys fins a 1977. Els estudiants que ocupaven les universitats, les vagues salvatges de l'obrer massa, els «indis metropolitans» que constituïen centres socials al hinterland de les metròpolis, les ràdios lliures, les revistes, les feministes que van reivindicar que «allò que és personal és polític» - de manera que es van polititzar la sexualitat i el treball domèstic_.... Tot això va ser, en definitiva, una explosió de creativitat que, malgrat la derrota, va encetar una nova etapa.

Dins de la història del feminisme, el de la diferència ha tingut un paper minoritari; tanmateix, en el període i el lloc en què ens situem, va tenir una importància majúscula. Les pràctiques de les feministes autònomes van sacsejar les plaques tectòniques sobre les quals s'assentaven alguns dels principis dels seus companys autònoms, i la resposta d'aquests en molts casos va ser violenta, com expliquem en aquest treball. Escindir el sexe en dos per demostrar la masculinització de què s'envoltava la igualtat va instaurar un «moment polític» a l'interior mateix del moviment. Les autònomes van interrompre l'ordre natural de dominació i es van instituir com a «part dels sense part» (Rancière, 1996).

\section{ORIGEN I PRESSUPÒSITS TEÒRICS: DESAFIANT CREONT}

El feminisme de la diferència italià té l'origen en el manifest programàtic del grup Desmitificació de l'Autoritarisme Patriarcal (DEMAU), l'any 1966. S'hi declara que «les dones no són un problema social, sinó que, més aviat, aquestes han de plantejar-se el problema que la societat els crea» (De las Heras Aguilera, 2009: 68). El col-lectiu DEMAU planteja l'affidamento (reconeixement de l'autoritat femenina i establiment de confiança mútua) com a manera de relacionar-se entre si.

El feminisme autònom, així com les diverses autonomies que van sorgir a Itàlia en la dècada dels setanta, comparteix amb l'operaisme' ${ }^{\mathbf{1}}$ el mètode amb què realitzen les aproximacions teòriques i la pràctica de la separació col-lectiva. Amb mètode ens referim a una aproximació a la realitat partint d'allò que Mario Tronti va denominar «produir un saber de part». Amb pràctica de la separació col-lectiva ens referim a soscavar les bases de la pròpia identitat per mitjà de la qual el subjecte de què es parteix és explotat. Aquests dos elements expliquen la crítica que fa Lonzi a Hegel i al marxisme leninisme i les teoritzacions de Silvia Federici sobre el treball domèstic, que comentem més avant.

L'any 1970 apareix el manifest fundacional de Rivolta Femminile i l'assaig Sputiamo su Hegel ('Escopim sobre

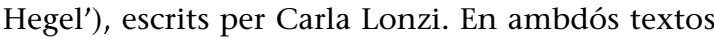

1 L'operaisme és un corrent del marxisme nascut a Itàlia en la dècada dels seixanta, l'elaboració del qual trobem a les revistes Quaderni Rossi i Classe Operaia. La particularitat d'aquesta «escola» és que atorga un paper central a les lluites obreres en el desenvolupament del capitalisme com a sistema històric i situa el al capital com a agent reactiu i el proletariat com a agent actiu, de manera que es proposa que la lluita contra el capitalisme parteix de la negació de la classe obrera com a força productiva (Tronti, 2001). 
s'analitzen i es critiquen les mateixes qüestions, de manera que ens centrarem a analitzar únicament l'assaig, l'extensió i l'argumentació del qual és major. ${ }^{2}$ Es planteja la demarcació amb les feministes de la igualtat i la crítica a un cert «democratisme» que aspirava a aconseguir una igualtat entre homes i dones per mitjà de la igualtat de drets. A partir d'alguns fragments del text, comentarem tres elements fonamentals criticats per Lonzi: la crítica al feminisme de la igualtat, al hegelianisme i al marxisme leninisme i a la família.

En la seua crítica al feminisme de la igualtat i a la noció d'igualtat entre sexes, Lonzi (2004: 5 i següents) estableix que:

La demanda d'igualtat entre dones i homes en el pla jurídic coincideix, històricament, amb l'afirmació de la igualtat dels homes entre ells [...] L'opressió de la dona no es resol amb la mort de l'home. No es resol amb la igualtat, sinó que prossegueix dins de la igualtat. No es resol amb la revolució sinó que es perpetua dins de la revolució [...] Per «igualtat de la dona» s'entén el seu dret a participar de la gestió del poder en la societat per mitjà del reconeixement que posseeix la mateixa capacitat que l'home [...] L'actuació de la dona no implica una participació en el poder masculí, sinó qüestionar el concepte de poder [...] La diferència és un principi existencial que es refereix als modes de l'ésser humà, a la peculiaritat de les seues experiències, de les seues finalitats i obertures, del seu sentit de l'existència en una situació donada i en la situació que vol donar-se.

Hi observem que la crítica que fa Lonzi a la «revolució» o al «poder» té a veure amb la seua masculinització, en tant que la dona és, històricament, «l'altra cara de la terra» (Lonzi, 2004: 45). Lonzi planteja que només des de la diferència es pot derrocar l'orde patriarcal, però, al seu torn, no refusa la inserció de la dona, sinó que sosté que la separació col-lectiva ha de produir-se en aquest mateix procés d'inserció.

2 Per consultar el manifest, vegeu Balestrini i Moroni (2006: 485 i següents).
En la divisió espai-gènere, l'home ocuparia l'espai públic vinculat amb el mode de producció (post) industrial en el qual es produeix l'explotació de l'home per l'home (capitalisme), i la dona, l'espai privat o domèstic vinculat al mode de producció domèstic en el qual es produeix l'explotació patriarcal (Noguera, 2016: 43-44). Per tant, per al feminisme de la diferència, no seria suficient aconseguir una igualtat en l'espai públic que reconega la dona com a ciutadana, sinó que s'hauria de transformar i alterar aquesta divisió espacial per mitjà de la separació i el qüestionament dels espais esmentats.

La crítica de Lonzi al hegelianisme és la crítica a la dialèctica de l'amo-esclau i, per tant, és la crítica al marxisme leninisme. Lonzi (2004: 9 i següents) s'hi planteja el següent:

El marxisme leninisme necessita equiparar ambdós sexes, però la venjança entre les col-lectivitats masculines no pot sinó traduir-se en un do paternalista dels valors masculins a la dona [...] La relació hegeliana amo-esclau és una relació interna del món humà masculí, i a això es refereix la dialèctica, en termes deduïts exactament de les premisses de la presa del poder [...] Incloure el problema femení dins d'una concepció de la lluita amo-esclau —com a lluita classista- és un error històric, ja que la dona prové d'una cultura que excloïa el punt de discriminació essencial de la humanitat, el privilegi absolut de l'home sobre la dona, i oferia a la humanitat perspectives en termes de la problemàtica masculina [...] Confiant el futur revolucionari a la classe obrera, el marxisme ha ignorat la dona com a oprimida i com a portadora de futur; ha expressat una teoria revolucionària, la matriu de la qual es troba en la cultura patriarcal.

En plantejar que la relació amo-esclau, així com la noció de classe, és una noció masculina igual que la relació amo-esclau —i la lluita de classes- està pensada des de la presa del poder i el poder s'ha configurat de manera patriarcal, Lonzi fa una crítica política i epistemològica. Política perquè implica una pràctica diferent d'aquella que es realitza des dels 
grups marxistes (per exemple, la creació de grups no mixtos) i epistemològica perquè fa referència a la manera des de la qual ens hem aproximat al món. En establir que hi ha una contradicció principal —que és la contradicció de classe- a partir de la qual es deriva i podem explicar la resta de les contradiccions, s'està partint d'una divisió sexual per la qual la dona ocuparia, dins de les societats capitalistes, una posició subordinada respecte a la del baró. Així, es confirmaria que «la història és el resultat de les accions patriarcals» (Lonzi, 2004: 15).

Pel que fa a la família, Lonzi l'entén com un element central de les societats patriarcals. En les seues pròpies paraules (Lonzi, 2004: 21 i següents):

Als països de l'àrea comunista, la socialització dels mitjans de producció a penes ha canviat l'estructura familiar tradicional [...]. La família és la pedra angular del sistema patriarcal: està fundada no sols en els interessos econòmics, sinó també en els mecanismes psíquics de l'home, que en totes les èpoques ha tingut la dona com a objecte de domini i com a pedestal per a les seues empreses més elevades [...]. L'abolició de la família no significa, de fet, constituir comunitats de dones - com Marx i Engels ja havien aclarit-, ni una altra fórmula que faça de la dona un instrument executiu del progrés, sinó l'alliberament d'una part de la humanitat que haurà fet sentir la seua veu i s'haurà enfrontat per primera vegada en la història no sols amb la societat burgesa sinó amb qualsevol tipus de societat projectada que tinga l'home com a protagonista, de manera que se situa així molt més enllà de la lluita contra l'explotació econòmica que denuncia el marxisme.

La crítica a la família als països socialistes serveix a Lonzi per a corroborar la seua tesi, prèviament definida, que sostenia que l'opressió de la dona es perpetua dins de la revolució. En assenyalar la família com a pedra angular del patriarcat, Lonzi descarta tot economicisme respecte a l'alliberament de la dona, és a dir, no n'hi ha prou amb aconseguir independència econòmica, sinó que, com déiem anteriorment, és necessari soscavar les bases que subordinen la dona demolint les divisions espacials que les constitueixen.

\section{5-1976: DE L'AUTOCONSCIÈNCIA A LA SEPARACIÓ COLLECTIVA}

Malgrat el desenvolupament teòric que s'ha realitzat, la construcció d'allò que Tarì (2016: 135) denomina «infraestructura d'un moviment» (constitució de grups, llibreries, editorials, revistes, espais de trobada, etc.) no va arribar fins l'any 1975. En el període anterior (1970-1974), va destacar la creació de dos revistes: l'Anabasis i Sottosopra. La pràctica dominant d'aquests grups era l' «autoconsciència», basada a elaborar un llenguatge compartit, privilegiar allò que s'ha viscut en l'àmbit personal i compartir aquestes vivències amb els altres (Tarì, 2016: 134).

En 1975, Lea Melandri, militant del moviment feminista i periodista italiana, va escriure una carta a Rosso, ${ }^{\mathbf{3}}$ que es va publicar el 18 d'octubre, en la qual, entre d'altres, es qüestionava la visió consumista de la felicitat:

Pel que fa a la reproducció i a la felicitat caldria admetre, si més no, que no és només una qüestió d'ingressos. Si no és així es creurà que els «rudes peons» aspiren, en definitiva, a la «felicitatfamiliar-en-el-supermercat» que veiem en els anuncis. En la reproducció i en la felicitat (és tan obvi que pareix ridícul haver de ressaltar-ho) entra en joc el cos, el seu ser sexuat, la qüestió històrica de la relació entre sexes (citat en Tarì, 2016: 137).

Començava a produir-se una revolució molecular que no tenia per objectiu assaltar l'Estat sinó transformar la vida; és a dir, la lluita pel salari domèstic, estar a favor de l'avortament lliure, la criança comuna i la invenció de noves vagues (Tarì, 2016: 139) posava de manifest que «allò que és personal és polític».

3 La revista Rosso (1973-1979) va ser una de les principals publicacions de l'autonomia italiana. 
Silvia Federici va escriure en la primavera de 1974 un text titulat «Salario contro il lavoro domestico», que en 1975 es va publicar per primera vegada com «Wages against Housework». En aquest text, Federici $(2004)^{4}$ estableix que la diferència entre rebre un salari o no per fer un treball rau en la naturalització que se'n produeix en el segon cas $i$, al seu torn, com que no es remunera el treball domèstic, s'estableix la no-consideració d'aquesta activitat com a treball, per a anticipar-se que les dones s'hi rebel-len, excepte en l'àmbit privat del dormitori-cuina. Per a Federici (2004: 39), la demanda del salari domèstic és «la demanda amb la qual acaba la nostra naturalesa i comença la nostra lluita, perquè el simple fet de reclamar un salari pel treball domèstic significa rebutjar aquest treball com a expressió de la nostra naturalesa». Per tant, el salari domèstic implica visibilitzar un tipus concret de relacions socials que en permet el rebuig. Reivindicar el caràcter assalariat del treball domèstic és el primer pas per a rebutjar haver de fer-lo (Federici, 2004: 40).

Molts militants autònoms no comprenien les formes particulars del moviment feminista. El 6 de desembre de 1975 es va produir una manifestació avortista a Roma a la qual van assistir vint mil dones. Els autònoms que hi volien participar havien de posarse a la part de darrere i deixar el protagonisme a les dones, la qual cosa va comportar l'enuig del servei d'ordre de Lotta Continua ${ }^{5}$ i d'alguns militants dels comités autònoms obrers romans que van agredir a colps de porres i de claus angleses dues manifestants, les quals van haver d'anar a l'hospital (Tarì, 2016: 140). L'autonomia organitzada no va reaccionar a l'uníson condemnant els fets, a excepció del grup $\mathrm{A} /$ traverso $^{6}$ —en aquell moment vinculat a escala

4 Hem utilitzat l'edició de Traficantes de Sueños en 2004, en la qual es recullen articles de la pensadora italiana entre 1975 i 2010.

5 Lotta Continua (1969-1976) era una organització d'esquerra extraparlamentària que formava part de l'autonomia obrera italiana.

6 A/traverso es va fundar a Bolonya l'any 1975 i després va donar lloc a la coneguda Radio Alice. Va destacar per la creativitat i per la reelaboració del llenguatge. organitzativa a Rosso-, que va publicar un document firmat com «alguns camarades de Bolonya» on manifestava que:

Tot això marca una línia de ruptura definitiva entre aquells que parlen d'autonomia, però pensen a reproduir la direcció centralitzada de la voluntat fàl-lica feta partit $-\mathrm{O}$, dit d'una altra manera, tracten d'instrumentalitzar les comissions femenines en la batalla contra el Govern-, i aquells que veuen l'autonomia com la capacitat de viure i posar en pràctica les pròpies necessitats, els propis desitjos al marge d'una lògica de negociació amb el Govern (citat en Tarì, 2016: 140).

En 1976, el moviment feminista va assolir la seua màxima extensió. L'eslògan més repetit era «tremate, tremate, li streghe son tornate» ('tremoleu, tremoleu, les bruixes han tornat'). Es van celebrar «rogles d'endimoniades» a Milà, «aquelarres» a Pàdua i «reprenguem la nit» (manifestacions nocturnes) a Roma, contra les quals la policia i els carabinieri van carregar moltes vegades (Tarì, 2016: 141). Les formes que adoptaven les manifestacions feministes —rogles de centenars de dones, cançons, disfresses, danses, performances teatrals, etc.- van obrir un debat intern en el grup de les autònomes entorn de la «folklorització» que podia sofrir el moviment a causa de la superficialitat d'aquest (Tarì, 2016: 141). L'historiador Marcello Tarì (2016: 141-142) sosté que, a pesar de tenir part de raó, aquestes teatralitzacions van ser les que van permetre que el feminisme no es quedara com a patrimoni d'unes poques dones «conscients», sinó que arribara a joves estudiants, mares, ancianes, xiquetes i intel-lectuals, infermeres i obreres.

\section{APRENENT DE LA DIFERÈNCIA. LLICCONS DE L'AUTONOMIA (A TALL DE CONCLUSIÓ)}

Creiem que hem exposat en aquest text les bases teòriques $\mathrm{i}$ els esdeveniments historicopolítics principals que van protagonitzar les feministes a Itàlia en la dècada dels setanta. Per concloure, incidirem 
en la tensió entre integració sense transformació i separació col-lectiva, interpretarem de manera gramsciana el feminisme autònom i assenyalarem la potencialitat constituent del feminisme de la diferència.

Pel que fa a la tensió entre integració sense transformació i separació col-lectiva, la visió de Lonzi és clara i ja s'ha exposat anteriorment: la separació col-lectiva es produeix en el procés mateix d'inserció. Davant d'interpretacions que puguen considerar la diferència com un rebuig frontal a la institucionalitat, nosaltres considerem que és més aviat una transformació radical de la institucionalitat patriarcal, és a dir, una subversió dels espais per mitjà dels quals s'ha construït la dominació masculina.

Si utilitzem de manera laica el llenguatge gramscià, tot i que hi haja risc que molts militants autònoms no hi estiguen d'acord, direm que l'autonomia - i a dins, el feminisme autònom - va suposar una «guerra de posicions ${ }^{7}$ prolongada. Dins d'aquesta, l'objectiu de

7 Gramsci entén que a Occident s'havia desenvolupat una «correlació eficaç entre Estat i societat civil» (Gramsci, 2013 255) que impedia la conquesta del poder polític per mitjà d'una ofensiva directa contra l'Estat, entés com a societat política, és a dir, una «guerra de moviments». Per consegüent, havia de produir-se una «guerra de posicions», que no és més que la disputa hegemònica a l'interior de la societat civil, i aquesta requereix «sacrificis enormes i masses immenses de població; per això, hi cal una concentració inaudita d'hegemonia i, per tant, una forma de govern més «intervencionista», que prenga més obertament l'ofensiva contra els grups d'oposició i organitze permanentment la «impossibilitat» de disgregació interna, amb controls de totes les classes, polítics, administratius, etc., consolidació de les «posicions» hegemòniques del grup dominant, etc.» (Gramsci, 2013: 262). les autònomes és la «despatriarcalització» del conjunt de relacions socials $i$, per tant, de les institucions a partir de les quals operen. Quan fem referència a les institucions, no ens estem cenyint al conjunt de poders públics encarregats de fer funcionar la societat política (vulgarment anomenada «Estat»), sinó a la solidificació d'unes relacions socials determinades en diferents espais. En aquest sentit, la «guerra de posicions» consisteix en la desnaturalització, politització i subversió de les institucions esmentades —emmarcades dins de la societat civil—, així com en la creació d'espais polítics que actuen com a nuclis contrahegemònics.

Aquests entronquen amb la potencialitat constituent del feminisme de la diferència. Com ha assenyalat Noguera (2016), una relació de la mateixa jerarquia entre el feminisme igualitarista i el feminisme de la diferència suposa l'ocupació d'espais vinculats a l'estructura estatal, als centres de treball, a l'esfera civil, etc., així com la creació de concepcions normatives i culturals de treball, gestió o administració diferents de les masculines-dominants. En aquest sentit, el discurs i la pràctica del feminisme de la diferència - i concretament la separació col-lectiva com a escissió en el procés d'inserció- plantegen superar les relacions de poder dominants i assumir com a presents les formes d'organització i estructuració de la societat que s'aspira a construir. Es configura així com un futur anterior.

\section{REFERÈNCIES BIBLIOGRÀFIQUES}

Balestrini, N. i Moroni P.(2006). La horda de oro (1968-1977): La gran ola revolucionaria y creativa, política y existencial. Madrid: Traficantes de Sueños.

De las Heras Aguilera, S. (2009). Una aproximación a las teorías feministas. Universitas. Revista de Filosofía, Derecho y Política, 9, 45-82.

Federici, S. (2004). Salarios contra el trabajo doméstico. En S. Federici, Revolución en punto cero: Trabajo doméstico, reproducción y luchas feministas. Madrid: Traficantes de Sueños. 
Gramsci, A. (2013). Antología. Madrid: Akal.

Lonzi, C. (2004). Escupamos sobre Hegel. Escritos de «Rivolta Femminile». Recuperat el 2 de maig de 2018 de https:// www.nodo50.org/herstory/textos/Escupamos\%20sobre\%20Hegel.pdf

Noguera, A. (2016). Superar la división espacio-género en sentido constituyente. En A. Guamán (coord.), Feminismos y procesos constituyentes. València: Tirant lo Blanch.

Rancière, J. (1996). El desacuerdo: Política y filosofía. Buenos Aires: Nueva Visión.

Tarì, M. (2016). Un comunismo más fuerte que la metrópoli: La Autonomía italiana en la década de 1970. Madrid: Traficantes de Sueños.

Tronti, M. (2001). Obreros y capital. Madrid: Akal.

Wallerstein, I. (2012). Capitalismo histórico y movimientos antisistémicos: Un análisis de sistema-mundo. Madrid: Akal.

\section{NOTA BIOGRÀFICA}

Graduat en Ciències Polítiques i de l’Administració Pública per la Universitat de València, actualment realitza estudis de posgrau en el CLACSO i un màster d'Estudis Llatinoamericans en la Universitat de Barcelona. 